\title{
Fluorescence-tagged metallothionein with CdTe quantum dots analyzed by the chip-CE technique
}

\author{
Ewelina Guszpit · Sona Krizkova • Marta Kepinska • \\ Miguel Angel Merlos Rodrigo • Halina Milnerowicz • \\ Pavel Kopel • Rene Kizek
}

Received: 9 July 2015/ Accepted: 15 October 2015/Published online: 28 October 2015

(C) The Author(s) 2015. This article is published with open access at Springerlink.com

\begin{abstract}
Quantum dots (QDs) are fluorescence nanoparticles (NPs) with unique optic properties which allow their use as probes in chemical, biological, immunological, and molecular imaging. QDs linked with target ligands such as peptides or small molecules can be used as tumor biomarkers. These particles are a promising tool for selective, fast, and sensitive tagging and imaging in medicine. In this study, an attempt was made to use QDs as a marker for human metallothionein (MT) isoforms 1 and 2. Four kinds of CdTe QDs of different sizes bioconjugated with MT were analyzed using the chip-CE technique. Based on the results, it can be concluded that MT is willing to interact with QDs, and the chip-CE
\end{abstract}

Electronic supplementary material The online version of this article (doi:10.1007/s11051-015-3226-8) contains supplementary material, which is available to authorized users.

E. Guszpit $(\bowtie) \cdot$ M. Kepinska $\cdot$ H. Milnerowicz Department of Biomedical and Environmental Analysis, Faculty of Pharmacy, Wroclaw Medical University, Borowska 211, 50-556 Wroclaw, Poland e-mail: ewelina.guszpit@gmail.com

S. Krizkova · M. A. M. Rodrigo - P. Kopel · R. Kizek Department of Chemistry and Biochemistry, Faculty of Agronomy, Mendel University in Brno, Zemedelska 1/1665, 61300 Brno, Czech Republic

S. Krizkova - M. A. M. Rodrigo - P. Kopel · R. Kizek Central European Institute of Technology, Brno University of Technology, Technicka 3058/10, 61600 Brno, Czech Republic technique enables the observation of their complexes. It was also observed that changes ranging roughly 6-7 kDa, a value corresponding to the MT monomer, depend on the hydrodynamic diameters of QDs; also, the MT sample without cadmium interacted stronger with QDs than MT saturated with cadmium. Results show that MT is willing to interact with smaller QDs (blue CdTe) rather than larger ones QDs (red CdTe). To our knowledge, chip-CE has not previously been applied in the study of CdTe QDs interaction with MT.

Keywords Bioconjugation - Chip-CE ·

Metallothionein · Quantum dots · Biomarkers ·

Health effects

$\begin{array}{ll}\text { Abbreviations } \\ \text { CE } & \text { Capillary electrophoresis } \\ \text { LDS } & \text { Lithium dodecyl sulfate } \\ \text { Mr } & \text { Molecular weight } \\ \text { MT } & \text { Metallothionein } \\ \text { NPs } & \text { Nanoparticles } \\ \text { QDs } & \text { Quantum dots }\end{array}$

\section{Introduction}

Metallothionein: structure and properties

MT was first isolated from a horse kidney in 1957 by Margoshes and Vallee as a cadmium binding protein 
of low molecular weight (about $6 \mathrm{kDa}$ ) (Margoshes and Vallee 1957). Nearly $30 \%$ of the protein consist of cysteines, each containing one SH group which gives them the ability to bind metal ions (Bremner and Beattie 1990; Duncan and Stillman 2006). MT plays an important role in the homeostasis of heavy metals (Coyle et al. 2002; Sabolic et al. 2010), protection against oxidative stress (Bizon et al. 2011; RuttkayNedecky et al. 2013), and DNA damage (Cai et al. 2000; Chubatsu and Meneghini 1993). MT is involved in the regulation of gene expression and transcription (Andrews 2000; Davis and Cousins 2000), enzyme activation (Krizkova et al. 2009a; Zalewska et al. 2014), and other biological processes.

Four major isoforms have been identified in mammals: MT-1, MT-2, MT-3, and MT-4 (Simpkins 2000). The best known isoforms MT-1 and MT-2 are expressed in nearly all types of tissues. Thanks to the presence of sulfur-based metal clusters in the particle, MT can bind with $7 \mathrm{Zn}$ (II), Cd (II) or $12 \mathrm{Ag}$ (I), Cu (I) ions per molecule. The MT binding affinity to metal ions differs between various metals or is metal dependent. For rat liver MT, the relative affinities of MT for Cd (II) were higher than for Zn (II) (Waalkes et al. 1984), while higher affinities of MT than for Cd (II) were found for $\mathrm{Cu}$ (I), $\mathrm{Hg}$ (II) and $\mathrm{Ag}$ (I) (Nielson et al. 1985; Hamer 1986). This indicates that Cd (II) ions can displace Zn (II) from MT structure. The main roles of MT-1 and MT-2 are detoxification of heavy metals from the body and protection against oxidative compounds (Bizon et al. 2011; Kagi and Schaffer 1988; Krizkova et al. 2010a; Moffatt and Denizeau 1997). MT-3 has been found mainly in the central nervous system (brain tissue), but also in kidneys, the heart, and reproductive organs, whereas MT-4 occurs in epithelial cells (Ruttkay-Nedecky et al. 2013; Vasak and Meloni 2011; Wang et al. 2006). MT-3 was first identified by Uchida et al. and originally termed a growth inhibitory factor (Uchida et al. 1991). MT-3 plays an important role not only in brain diseases, particularly in Alzheimer's disease, but also in Parkinson's disease and cognitive disorders (Carpene et al. 2007; Craig-Schapiro et al. 2009; Manso et al. 2012; Vasak and Meloni 2011).

Changes in the expression of MT could be a prognostic marker in the development of tumor malignancies, such as breast, prostate, ovary, head, and neck, or small-cell lung cancer, melanoma, and soft tissue sarcomas (Cherian et al. 2003; Krizkova et al. 2009b; Krizkova et al. 2010b; Krizkova et al. 2011; Namdarghanbari et al. 2011). However, the expression level of this protein is not universal for all human tumors and may depend on the state of tumor proliferation. Over the last decade, some data have appeared illustrating that induction of MT can be used as an adjunct in cancer chemotherapy, to prevent the toxicity caused by gamma radiation or the action of cisplatin, as well as by other chemotherapeutic agents (Doz et al. 1993; Karotki and Vasak 2009; Koberle et al. 2010; Sogawa et al. 2013). Previously published papers show that there are significant problems with the identification and monitoring of MT expression and its concentration. The challenge is to develop techniques for a selective, sensitive, and rapid labeling of this protein.

Preparation of QDs and their application

Because of the changes in structural and functional properties, resulting from reductions in their size, nanomaterials have become very popular. An additional advantage of NPs is the ability to obtain biocompatible molecules in nanoscale which allows for quick and easy use of NPs in the field of science and industry (Niemeyer 2001; Rana et al. 2010; Roco 2003; Salata 2004; Sanvicens and Marco 2008). Of equally large significance is the development of fluorescent labeling techniques, due to the possibility for their use in treatment of individual marking (targeted therapy) (Brannon-Peppas and Blanchette 2012; Liu et al. 2007), molecular imaging, and also in chemical and biochemical assays (Drbohlavova et al. 2009; Rao et al. 2007; Terai and Nagano 2013). With the evolution of nanotechnology, the search for new biocompatible markers has led to the emergence of luminescent materials with properties known as semiconductor quantum dots (QDs) and lanthanidedoped nanocrystal (Drbohlavova et al. 2009; Gao et al. 2005; Smith et al. 2004; Wang and Li 2007).

QDs are nanocrystals with structures containing metal atoms of groups II-VI (e.g., CdS, CdTe, ZnSe) or III-V (e.g., InP, InAs) of the periodic table (Chan et al. 2002). Luminescence of the particles is due to quantum effects associated with changes permitted in electron states. QDs are characterized by the emission of visible light (depending on the size of the NPs) after ultraviolet irradiation (UV) (Drbohlavova et al. 2009; Michalet et al. 2005; Smith et al. 2004). 
During the process of QDs preparation, it is possible to control such conditions as time, temperature, and type of ligand, thus obtaining the desired crystallite size and shape. The spectroscopic properties of QDs strongly depend on the size and shape of the crystallites (Alivisatos 1996; Drbohlavova et al. 2009; Gao et al. 2005). Moreover, the choice of ligand to the bioconjugation, such as an antibody or protein with a good affinity, allows the use of specific QDs for labeling DNA, proteins, or even cells (Chan and Nie 1998; Frasco and Chaniotakis 2010).

The majority of QDs that have been studied and used are those which in the core have selenium or tellurium atoms, because of the wide range of spectrum emitted by the region containing the atoms of these elements (Drbohlavova et al. 2009; Frasco and Chaniotakis 2010; Michalet et al. 2005; Smith et al. 2004). In order to reduce the cytotoxicity of QDs and improve their spectroscopic properties (e.g., elimination of photobleaching), different synthesis methods have been developed (Chan et al. 2002; Grieve et al. 2000; Michalet et al. 2005; Wang and Li 2007). Another way to reduce QDs cytotoxicity to an acceptable level is by coating their surface. The surface coating of QDs is mainly due to their stability, as without it they tend to aggregate and lose fluorescence. Additionally, it protects the nanocrystallites from chemical degradation. QDs may be safely used as fluorescent probes in biological labeling, markers for monitoring drug release, and for controlled modification of structural and functional properties of intracellular components (Alivisatos 1996; Chan et al. 2002; Chan and Nie 1998; Derfus et al. 2004; Dubois et al. 2007; Frasco and Chaniotakis 2010; Grieve et al. 2000; Hoshino et al. 2004; Michalet et al. 2005; Wang and Li 2007).

\section{Chip-CE technique}

Capillary electrophoresis (CE) is often used to detect MT and to separate isoforms of MT (Minami et al. 2002; Richards and Beattie 1995; Ryvolova et al. 2012; Zalewska et al. 2011). CE techniques constitute a family of electrokinetic methods. During CE analysis through capillaries or micro and nanochannels, analytes migrate under the influence of the applied voltage. Separation in these methods is based on ionic mobility (Righetti et al. 2013; Sieradzka et al. 2014; Zhu et al. 2012). In addition, CE can also be used for monitoring MT concentration during illness, as well as analyzing stability and affinity in the conditions of an experimental environment (Petersen et al. 2003; Ryvolova et al. 2012; Swinney and Bornhop 2000). It is also proposed to apply this technique in experiments involving modification of MT and its ability to form aggregates and polymers (Krizkova et al. 2009a).

Due to the presence of two domains in the MT structure: $\beta$-domain $\left(\mathrm{N}\right.$-terminus, $\left.\mathrm{Me}(\mathrm{II})_{3} \mathrm{Cys}_{9}\right)$ and $\alpha$ domain (C-terminus, $\mathrm{Me}(\mathrm{II})_{4} \mathrm{Cys}_{11}$ ) and the high affinity to bind $\mathrm{Cd}$ because of $\mathrm{Cd}-\mathrm{S}$ bond formation, it is possible to observe the interaction of CdTe with MT (Skalickova et al. 2013; Thormann et al. 2001). For the determination of bioconjugates of QDs with MT, a technique is needed that allows for the simultaneous analysis of several samples with high efficiency in a relatively short time. Chip-CE can be used as a tool to effectively and efficiently analyze the marking of MT with QDs. To our knowledge, chip-CE has not been applied in the study of CdTe nanoparticles interaction with MT to date.

In this study, we have attempted to show the differences in the interaction of QDs with human MT, which depend on different sizes of QDs. The obtained complexes were analyzed using chip-CE and fluorescence intensity.

\section{Experimental}

\section{Chemicals}

Chemicals such as mercaptosuccinic acid (MSA), cadmium acetate, cadmium chloride (99.999\%), and sodium tellurite were purchased from Sigma Aldrich (St. Louis, MO, USA). Two stock solutions ( $50 \mu \mathrm{g} / \mathrm{mL}$ of Cd(II) and $500 \mu \mathrm{g} / \mathrm{mL}$ of MSA) were prepared daily and subsequently diluted to the appropriate concentration just prior to use. As a supporting electrolyte, $0.2 \mathrm{M}$ acetate buffer of $\mathrm{pH} 5$ was used. High-purity deionized water was used throughout the study (Milli-Q Millipore $18.2 \mathrm{M} \Omega / \mathrm{cm}$, Bedford, MA, USA).

Sample preparation

Human liver metallothionein was obtained according to procedure described previously (Milnerowicz and Bizon 2010). Briefly, pieces of human liver were washed several times with PBS (the study protocol was approved by the Local Bioethics Committee (KB No 
165/1999)). The tissue was homogenized in a buffer (10 mM Tris/HCl, pH 8.6, $10 \mathrm{mM} \beta$-mercaptoethanol and $25 \mathrm{mM}$ sucrose) with a ratio of 1:4 $(\mathrm{v} / \mathrm{v})$. The resulting homogenate was centrifuged each time at $4{ }^{\circ} \mathrm{C}$ in three stages under the following conditions: $1-$ $5000 \times g$ speed for $25 \mathrm{~min}, 2$-speed of $10,000 \times g$ for $1 \mathrm{~h}, 3$-speed $105,000 \times g$ for $2 \mathrm{~h}$. The obtained supernatant was separated into two samples wherein one of them (Cd-MT) was saturated with $\mathrm{CdCl}_{2}$ and incubated in a water bath at $80{ }^{\circ} \mathrm{C}$ for $10 \mathrm{~min}$ and stirred. Both cytosol fractions (nonCd-MT and Cd-MT) were precipitated with acetone in scope from $60 \%$ to $80 \%$ (left overnight). After centrifugation, the resulting precipitates were dissolved in Tris- $\mathrm{HCl} \mathrm{pH} 8.6$ and centrifuged again. The samples were applied to a Sephadex G-75 column. Fractions containing MT were verified by SDS/PAGE, Western Blot, and ELISA (Milnerowicz and Bizon 2010). The samples containing human MT (both isoforms MT-1 and MT-2) were concentrated by Cut-off filter $3 \mathrm{~K}$ (Amicon Ultra- 0.5 Centrifugal Filter Devices) prior to analysis on MALDI-TOF/TOF (supplementary material 2).

\section{CdTe QDs synthesis}

The method of CdTe QDs preparation was previously published by Duan et al. (2009). A spare solution of CdTe QDs was prepared by dissolving cadmium acetate dihydrate $(0.044 \mathrm{~g})$ in $76 \mathrm{~mL}$ of MiliQ water in a $200 \mathrm{~mL}$ beaker on a magnetic stirrer. Then, mercaptosuccinic acid (MSA) $(60 \mathrm{mg})$ in water $(1 \mathrm{~mL})$ was added followed by $1.8 \mathrm{~mL}$ of $1 \mathrm{M} \mathrm{NH}_{3}$. Finally, a solution of $\mathrm{Na}_{2} \mathrm{TeO}_{3}(0.0055 \mathrm{~g})$ in water was added and after a few minutes $40 \mathrm{mg}$ of $\mathrm{NaBH}_{4}$ was poured into the stirred solution. The solution was stirred for $1 \mathrm{~h}$, its volume was adjusted to $100 \mathrm{~mL}$ with the addition of water, after which it was heated in vials filled with $2 \mathrm{~mL}$ of the solution in a Multiwave 300 microwave oven (Anton Paar GmbH, Graz, Austria) (300 W, $10 \mathrm{~min}$ ). CdTe QDs were prepared at various temperatures according to emission color $\left(50{ }^{\circ} \mathrm{C}\right.$-blue, $70^{\circ} \mathrm{C}$ green; $90{ }^{\circ} \mathrm{C}$-yellow; $130{ }^{\circ} \mathrm{C}$-red, Fig. 1).

\section{Dynamic light scattering}

The average particle hydrodynamic parameter and diameters distribution of the nanoparticles were determined by a Zetasizer (Malvern-zetasizer Nano $\mathrm{ZS}$, Malvern, UK) at $25^{\circ} \mathrm{C}$. The measurement was

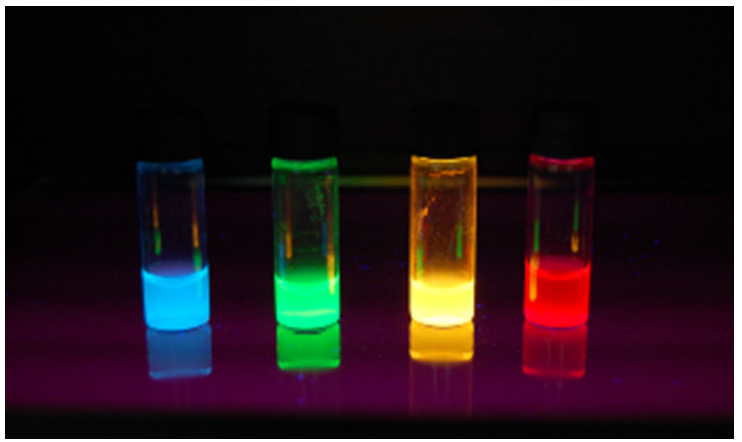

Fig. 1 Picture shows synthetic blue, green, yellow and red QDs respectively after ilumination using UV transiluminator (254 $\mathrm{nm})$. (Color figure online)

performed after diluting the solution with deionized water. Size as hydrodynamic diameter is modeled by Stokes-Einstein equation (Murdock et al. 2008). The hydrodynamic parameter of quantum dots increased with the increasing temperature of the preparation process. The sizes (hydrodynamic diameters) of the nanoparticles were as follows: $3.4 \mathrm{~nm}$ (blue QDs), $3.8 \mathrm{~nm}$ (green QDs), $4.5 \mathrm{~nm}$ (yellow QDs), and $5.2 \mathrm{~nm}$ (red QDs).

\section{Conjugation of QDs with MT}

$4 \mu \mathrm{L}$ of each sample of Cd-MT and nonCd-MT consisting of both isoforms (MT-1 and MT-2) at a concentration $0.1 \mathrm{mg} / \mathrm{mL}$ was mixed with $4 \mu \mathrm{L}$ of each QDs. The mixture was incubated for $2 \mathrm{~h}$ at $20{ }^{\circ} \mathrm{C}$ in a thermoblock (Eppendorf thermomixer, Germany).

\section{Chip-CE}

Analyses using an automated microfluidic Experion electrophoresis system (Bio-Rad, USA) were carried out according to the manufacturer's instructions with supplied chemicals (Experion Pro260 analysis kit, Bio-Rad). The kit allows for fast and reproducible protein analysis with a separation range of $10-260 \mathrm{kD}$ with $2.5 \mathrm{ng} / \mu \mathrm{L}$ sensitivity; detection was performed using colloidal Coomassie Blue gel staining. The presence of the ladder (as a standard) allowed correlation of migration time with molecular weight. A sample analysis was carried out according to the following steps:

1. Priming the chip-microchannels were filled in with the microfluidic gel-stain solution (with 
fluorescent dye). $0.2 \mu \mathrm{g}$ of both MT samples (nonCd-MT and Cd-MT) was used per one chipCE sample. A $4 \mu \mathrm{L}$ of each sample was mixed with $2 \mu \mathrm{L}$ of non-reducing sample buffer without heating ( $30 \mu \mathrm{L}$ of the sample buffer with $1 \mu \mathrm{L}$ of water), and $84 \mu \mathrm{L}$ of water was added. The ladder was prepared in reducing conditions $(30 \mu \mathrm{L}$ of the sample buffer with $1 \mu \mathrm{L}$ of $\beta$-mercaptoethanol (total concentration of $\beta$-mercaptoethanol is $\left.3.3 \%(\mathrm{v} / \mathrm{v}), 95{ }^{\circ} \mathrm{C}, 5 \mathrm{~min}\right)$. After priming the chip with the gel and gel-staining solution, the sample $(6 \mu \mathrm{L})$ was loaded into the sample well. The Pro260 Ladder included in the kit was used as a standard.

2. The prepared chip was inserted into the electrophoresis station. During separation performed at $21{ }^{\circ} \mathrm{C}$ (voltage: $100-240 \mathrm{~V}$ ), the fluorescent dye associated with the lithium dodecyl sulfate (LDS) coating the proteins.

3. As the molecules migrated towards the end of the separation channel, a laser excited the dye, causing it to fluorescence (Bousse et al. 2001).

Fluorimetric measurement

Fluorescence and absorbance spectra were acquired with a multifunctional microplate reader EnSpire Multimode Reader (PerkinElmer, USA). The absorbance scan was measured within a range of 350-750 nm (Fig. 2a). Based on the results obtained, $400 \mathrm{~nm}$ was used as an excitation wavelength and the fluorescence scans were measured within the range from $440-840 \mathrm{~nm}$ per $5 \mathrm{~nm}$ steps (Fig. 2b). Each intensity value is an average of 5 measurements. $15 \mu \mathrm{L}$ of each QDs were mixed with $15 \mu \mathrm{L}$ of each sample of nonCd-MT and Cd-MT (consisting of two isoforms (MT-1 and MT-2) with the concentration of $0.1 \mu \mathrm{g}$ ). After $2 \mathrm{~h}$ of incubation, the mixed samples were placed in a transparent 96-well microplate with a flat bottom by Nunc (Thermo Scientific, USA).

\section{Results}

The synthesized QDs exhibited various colors after excitation with UV light $(254 \mathrm{~nm})$ (Fig. 1). The resulting products were characterized with the use of fluorescence spectroscopy (Fig. 2b). After interaction of QDs with Cd-MT and nonCd-MT ( $2 \mathrm{~h}$ incubation of each QD with each MT sample, for details see Material and Methods section), different fluorescent behaviors of Cd-MT and nonCd-MT was observed (Fig. 3). On the fluorescence intensity spectra, higher peaks were present for nonCd-MT with blue QDs (675 AU) and with red QDs (1440 AU) than for lone blue QDs (221 AU) and red QDs (1136 AU), respectively (Figs. 2b, 3a). The fluorescence intensity was the same for yellow QDs with nonCd-MT (1409 AU) and yellow QDs (1409 AU, Fig. 2b), whereas the peak obtained for green QDs with nonCd-MT (1590 AU) was lower than the peak for green QDs alone (2098 AU) (Fig. 3a).

The fluorescence intensity spectrum for Cd-MT shows higher peaks for Cd-MT with blue QDs and red QDs (415 AU and 1820 AU, respectively, Fig. 3b)
Fig. 2 Absorbance (a) and fluorescence spectra (b) of blue, green, yellow and red QDs. (Color figure online)
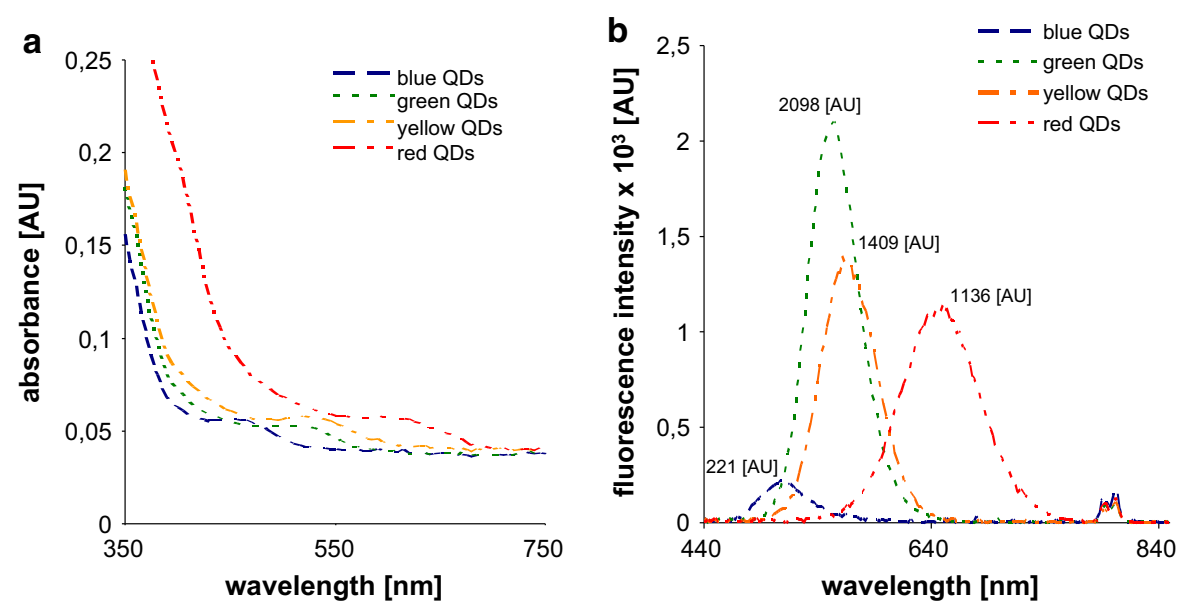

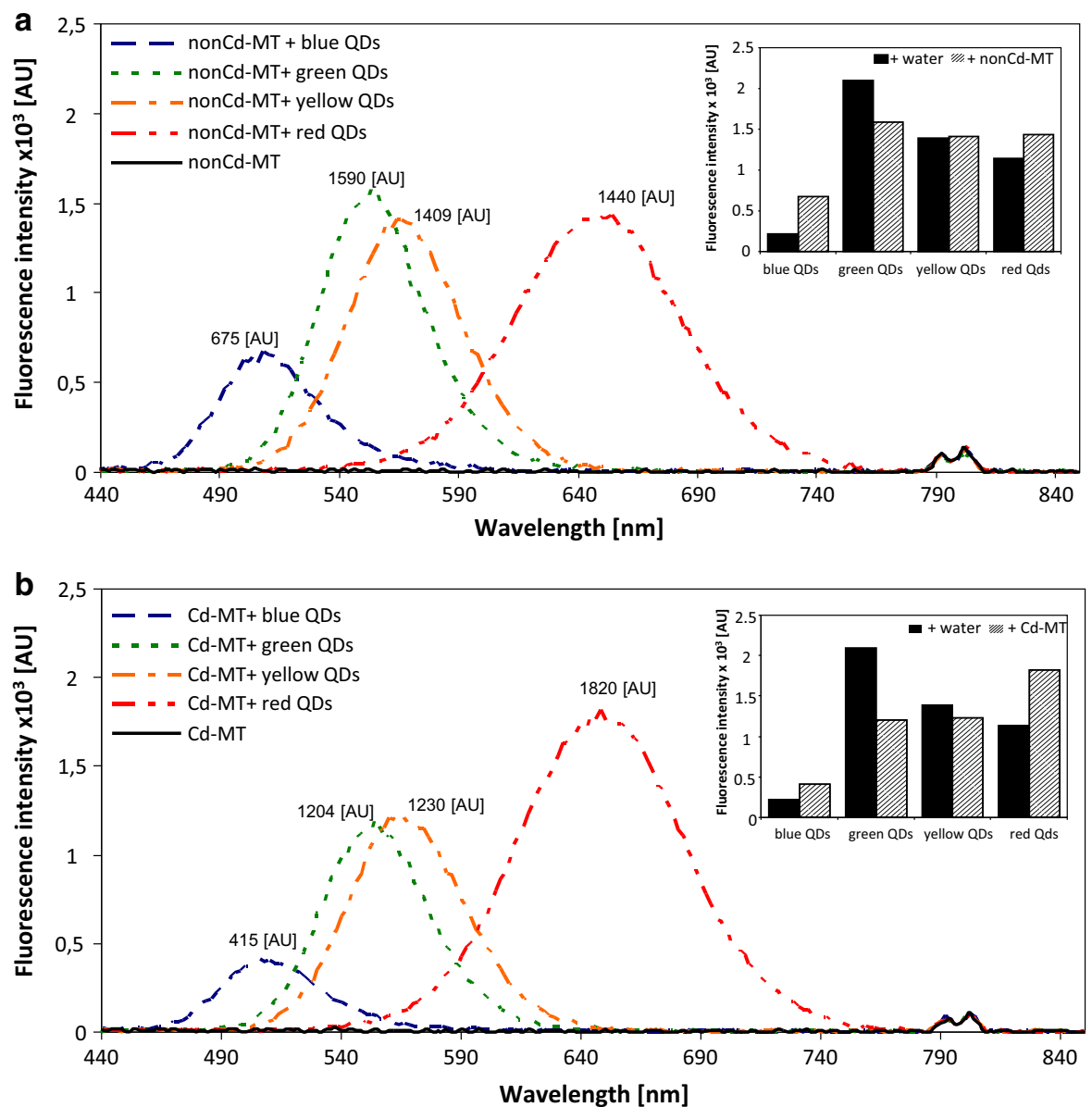

Fig. 3 Fluorescence intensity of bioconjugated QDs with (a) nonCd-MT and (b) Cd-MT. In insets are shown the differences obtained in emission maxima. (Color figure online)

compared to the peaks obtained for blue and red QDs alone (Fig. 2b). The peaks obtained for Cd-MT with green QDs (1204 AU) and yellow QDs (1230 AU) (Fig. 3b) were lower than the peaks obtained for green and yellow QDs alone (Fig. 2b).

On the fluorescence spectra, it was observed that the peak obtained for Cd-MT + red QDs (1820 AU) was higher than the peak obtained for nonCd-MT (1440 AU) (Fig. 3a, b). However, the peaks obtained for nonCd-MT with blue (675 AU), green (1590 AU), and yellow QDs (1409 AU) (Fig. 3a) were higher than the peaks obtained for Cd-MT with blue (415 AU), green (1204 AU), and yellow QDs (1230 AU), respectively (Fig. 2b).

Interaction of Cd-MT and nonCd-MT with QDs was studied also using chip capillary electrophoresis. The chip-CE electropherogram for nonCd-MT shows three main peaks sized $3.2 \mathrm{kDa}, 7.0 \mathrm{kDa}$, and $15.4 \mathrm{kDa}$ corresponding to migration times at: 24.0 , 28.2, and $34.0 \mathrm{~s}$, respectively (Fig. 4a, b). The signal of the system peak for nonCd-MT characterized by a time shift in the migration time range of 23.7-30.0 s (1.9-7.0 kDa) could be compared to the ladder system peak, which was detected at $28 \mathrm{~s}(6.8 \mathrm{kDa})$ (supplementary material 2).

On the electropherograms with Cd-MT, three main peaks were observed with the sizes of 6.0, 9.2, and $40 \mathrm{kDa}$ corresponding to migration times at 27.2,30.7, and $41.5 \mathrm{~s}$, respectively (Fig. 4c, d). Signal of the system peak for Cd-MT characterized by the time shift in migration time range 23.6-30.4 s $(2.9-8.9 \mathrm{kDa})$ could be compared to the ladder system peak, which was detected at $28 \mathrm{~s}(6.8 \mathrm{kDa})$ (supplementary material 2). 

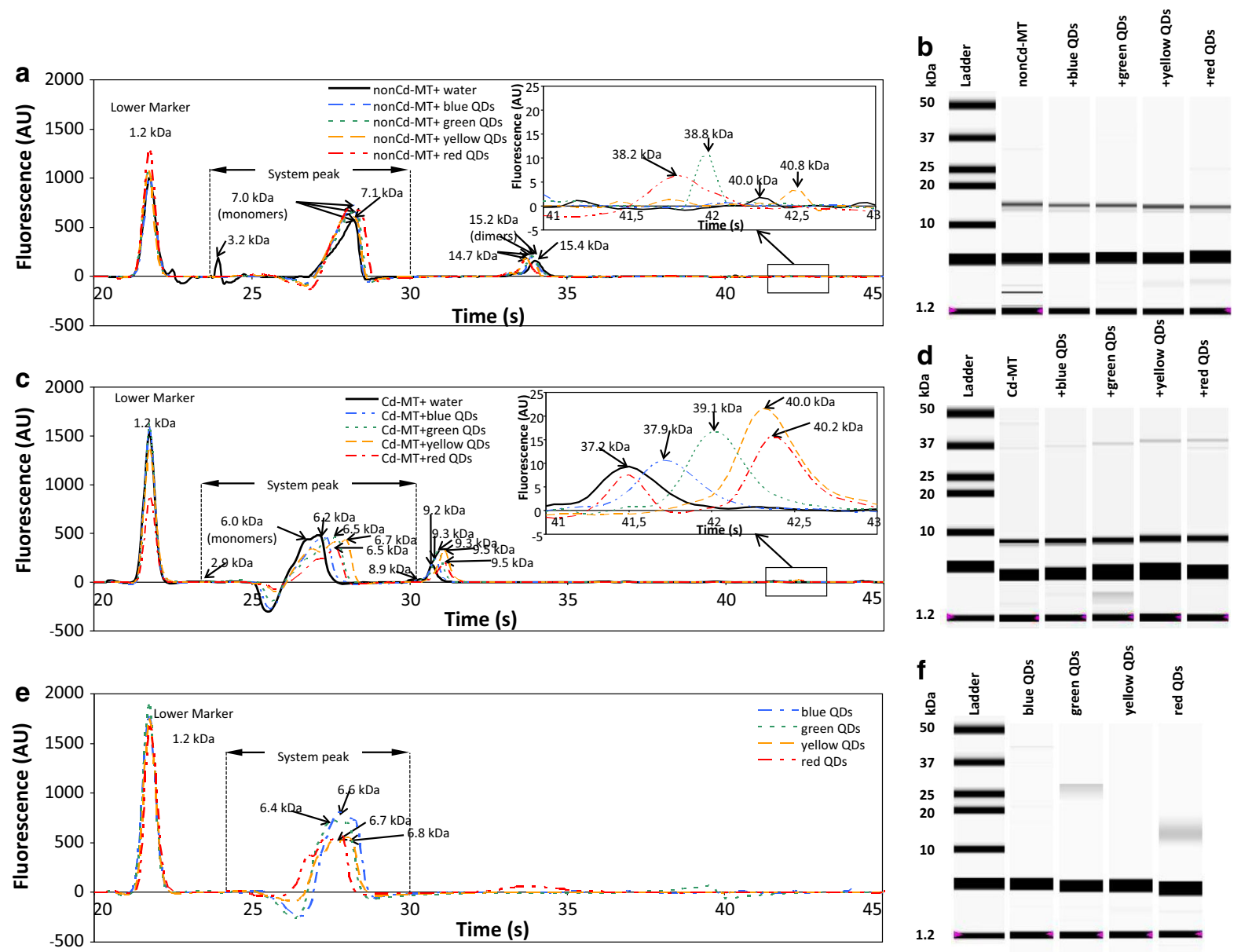

Fig. 4 Electrophoreograms of: (a) bioconjugated nonCd-MT with QDs, (c) bioconjugated Cd-MT with QDs and (e) QDs. (b), (d) and (f) are a gel of nonCd-MT with QDs, Cd-MT with QDs and four QDs respectively. (Color figure online)

The obtained peaks for both samples (nonCd-MT and (d-MT) with Mr of roughly 6-7 $\mathrm{kDa}$ indicated the presence of MT monomers; however, the monomers co-migrated with a system peak, and thus, their correct sizing is not possible. For nonCd-MT, an additional peak with $15.4 \mathrm{kDa}$ was noted, which may indicate the presence of dimers MT (Fig. 4a, b). For Cd-MT, an additional peak was noted at about 37-40 kDa which may indicate the presence of oligomers. The graphs show shifted peaks and differences in $\mathrm{Mr}$ for nonCdMT monomers $(\mathrm{Mr}=7.0 \mathrm{kDa}, t=30.0 \mathrm{~s})$ and $\mathrm{Cd}-$ MT monomers $(\mathrm{Mr}=6.0 \mathrm{kDa}, t=27.2 \mathrm{~s})$. Furthermore, differences in the migration time (and $\mathrm{Mr}$ ) for the second main peak were observed at $36.3 \mathrm{~s}$ $(15.4 \mathrm{kDa})$ for nonCd-MT and at $30.7 \mathrm{~s}(9.2 \mathrm{kDa})$ for Cd-MT.

To prove that the signals observed for samples of MT bioconjugated with QDs were not derived from
QDs, an electropherogram was performed for four different QDs (Fig. 4e, f). The peaks for blue, green, yellow, and red QDs alone corresponded to $6.6 \mathrm{kDa}(t=27.6 \mathrm{~s}), 6.4 \mathrm{kDa}(t=27.4 \mathrm{~s}), 6.8 \mathrm{kDa}$ $(t=28.0 \mathrm{~s})$, and $6.7 \mathrm{kDa}(t=27.6 \mathrm{~s}) \mathrm{Mr}$, respectively (Fig. 4e, f). The range migration times for systems peaks were observed at $24.5 \mathrm{~s}(2.5 \mathrm{kDa})-$ $29.5 \mathrm{~s}(6.6 \mathrm{kDa})$ for blue QDs, $24.3 \mathrm{~s}(2.3 \mathrm{kDa})-$ $29.7 \mathrm{~s}(6.7 \mathrm{kDa})$ for green QDs, $24.9 \mathrm{~s}(2.8 \mathrm{kDa})-$ $29.8 \mathrm{~s} \quad(6.9 \mathrm{kDa})$ for yellow QDs, and $24.8 \mathrm{~s}$ (2.7 kDa)-29.6 s (6.7 kDa) for red QDs (Fig. 4e). It was observed that the system peak obtained for nonCd-MT was shifted in time when compared to the system peaks obtained for each QDs (Fig. 4a, e).

The graphs in Fig. 4a show that the addition of CdTe QDs to nonCd-MT led to the intensities of the peaks at $28 \mathrm{~s}$ increasing, which may be explained by the formation of QDs-(nonCd-MT) complexes. The 
observed fluorescence intensity for peaks at the positions of roughly 28, 34, and $41 \mathrm{~s}$ for blue and red QDs-nonCd-MT complexes was higher than the fluorescence intensity obtained for others QDs+nonCd-MT complexes (Fig. 4a). It shows that nonCd-MT prefers to interact with blue and red QDs rather than with others QDs.

The peak at about $34 \mathrm{~s}(\mathrm{Mr}=15 \mathrm{kDa})$ may indicate the presence of MT dimers (Fig. 4a, b). The graphs show that MT dimers are likely to combine with green QDs rather than with blue ones (Fig. 4a), which corresponds to the larger increase in the peak obtained for green QDs-(nonCd-MT) complexes rather than blue QDs-(nonCd-MT) when compared to nonCd-MT.

In the case of Cd-MT, the addition of QDs (Fig. 4c, d) shows that peaks observed for Cd-MT complexes with QDs at 27 s decreased and shifted towards higher $\mathrm{Mr}$ in comparison with Cd-MT. It was observed that the largest number of Cd-MT particles bound to the smallest sized QDs (blue QDs) (Fig. 4c). Intensities of the peaks for complexes of Cd-MT with green and yellow QDs observed at 31 s were slightly increased, while intensities for the complexes of Cd-MT with blue and red QDs were comparable to Cd-MT alone, but with time shifted towards higher $\mathrm{Mr}$ depending on their size (Fig. 4c). For green QDs, the obtained peak occurred later in time, which means that larger aggregates of cadmium MT are more likely to combine with them than with the smaller ones (blue $\mathrm{CdTe}$ ) or the largest ones (red CdTe, Fig. 4c, d).

At the position of roughly $41 \mathrm{~s}(\mathrm{Mr} 37.2 \mathrm{kDa}$ for Cd-MT) (Fig. 4c), new peaks occurred for all complexes of QDs with Cd-MT (Fig. 3c, d). Increased intensities at 41-43 s were observed for complexes of Cd-MT with yellow (the highest) and green and red (similar intensities) QDs compared with Cd-MT alone $(t=41.5 \mathrm{~s}, 37.2 \mathrm{kDa})$. At $42-43 \mathrm{~s}$, a time shift towards higher $\mathrm{Mr}$ for all QDs was also observed (e.g., $39.1 \mathrm{kDa}$ for Cd-MT+green QDs, $40.0 \mathrm{kDa}$ for Cd-MT+yellow QDs) (Fig. 4c).

\section{Discussion}

A large number of publications have been reported on the validity of the determination of MT as a tumor marker (Cherian et al. 2003; Krizkova et al. 2010b; Krizkova et al. 2011). An important factor would be the selection of such a method that would allow for both sensitive and selective analysis of MT presence in body fluids.

The application of QDs as a marker for peptides (Rosenthal et al. 2011), proteins (Miyawaki et al. 2003) or DNA (Mitchell et al. 1999) is well known. Using luminescence QDs as a tumor biomarker seems to be an effective method of tagging at the molecular level (Chan et al. 2002; Gao et al. 2005; Mitchell et al. 1999). The mechanisms by which QDs bind to biomolecules are still being explored (Gao et al. 2005; Mitchell et al. 1999; Miyawaki et al. 2003; Pons et al. 2006). It is worth mentioning the fact that the type of interaction depends on the geometric orientation of biomolecules and hydrodynamic sizes of QDs (Michalet et al. 2005; Pons et al. 2006). Researchers point out that QDs can interact with proteins through the presence of cysteine residues (Miyawaki et al. 2003; Rosenthal et al. 2011). The use of QDs in medicine and biochemistry appears to be a promising technique that allows for quick labeling and analysis of proteins. The advantage of this technique seems to be the ability to control and influence the properties of QDs through manipulation in the selection of ligand or a change of reaction (Chan et al. 2002; Michalet et al. 2005). In addition, QDs can provide usable imagery due to their fluorescent properties. It is important to ensure the safety and reduce the cytotoxicity of these probes, for example, by decreasing the surface defect density (Silva et al. 2014). In the cited article, the authors showed that increasing concentrations of Se reduced the toxic effects of CdSe QDs. It was noted that due to the affinity of cadmium to MT, the interaction of this protein with CdTe QDs is possible, and that reduced presence of $\mathrm{Cd}^{2+}$ diminished the expression of MT mRNA (Silva et al. 2014).

The interaction of MT with QDs is known, and it has been described using spectrophotometry, fluorimetry and voltammetry (Skalickova et al. 2013). Through spectral and electrochemical techniques, it was possible to locate signals of MT after interaction with QDs in $\mathrm{Mr}$ corresponding to MT dimers or trimers (Tmejova et al. 2014). Oligomerization of MT after interaction with metals or after oxidation was previously studied with CE, MS (Hong et al. 2000; Shen et al. 2006), spectrophotometry (Palumaa and Vasak 1992), and chip-CE (Krizkova et al. 2010a). The interaction of MT with QDs can occur not only under in vitro conditions but also in living organisms, 
as a part of heavy metals detoxification resulting in biosynthesis of MT-stabilized QDs (Skalickova et al. 2013; Sturzenbaum et al. 2013; Trabelsi et al. 2013).

The chip-CE technique was proposed for the first time for analysis of MT by Krizkova et al. (Krizkova et al. 2009a). The authors showed that this technique can be used to analyze MT, including to investigate the effects of oxidation on the structure of MT. Many commercial platforms for chip electrophoresis allowing routine analysis of nucleic acids or proteins are available, and their use for NPs analysis has been tested (Smejkal and Foret 2012). One such example is the use of this technique for the detection of AgNPs in common water (Chua and Pumera 2013).

The interactions of MT with QDs described above were analyzed using various techniques, and the chipCE technique was used to analyze MT as well as QDs, but to our knowledge, chip-CE has not previously been used for studying interactions of MT with CdTe QDs. Our results indicate that this technique is suitable for monitoring proteins interacting with NPs. The observed increased intensity of peaks for MT-QDs complexes allows for the use of chip-CE to detect QDs binding to MT. Unfortunately, due to the presence of system peaks, an accurate analysis of the MT monomer is not possible, and it is suspected that a peak derived from the MT monomer is blocked by the system peaks (Krizkova et al. 2009a). Nevertheless, the signal corresponding to the amount of the protein bound or unbound with QDs allows determination of binding of MT-QDs depending on the size of CdTe. The chip-CE technique successfully enabled the imaging bioconjugation of these QDs with MT, which can be used in monitoring and identification of this protein. In this study, we used chip-CE to verify complexes generated in the process of bioconjugation of different sizes of CdTe with MT. The interaction between MT and QDs was also verified using fluorescence intensity.

As shown in this report, MT readily combines with the proposed CdTe due to its affinity for Cd. While in nonCd-MT complexes with QDs, only slight changes in peaks' intensities were observed, in Cd-MT, it was observed that additional changes in peaks' time migration appeared, resulting in a shift to higher $\mathrm{Mr}$ for Cd-MT complexes with QDs (depending on the hydrodynamic diameter of the QDs) compared to MT alone. The changes in migration time were most distinctive for green and yellow QDs. Moreover, for
Cd-MT, we observed new peaks in positions of $37 \mathrm{kDa}$, which were shifted depending on the size of QDs. The choice of the size of CdTe QDs allowed us to analyze not only the MT monomers but also the MT oligomers in the sample.

The increase of $31 \mathrm{~s}$ peak at Cd-MT-QDs indicated that MT dimers (10 and $15 \mathrm{kDa})$ exhibit a higher affinity with QDs in a Cd-saturated state and form oligomers $(40 \mathrm{kDa})$ depending on QDs size (for Cd$\mathrm{MT}+$ red QDs complexes, the intensity decreased at 27 and $31 \mathrm{~s}$ but at $41 \mathrm{~s}$ increased compared to Cd-MT alone). Also, on the fluorescence intensity spectra, it can be noticed that the peak obtained for Cd-MT+red QDs was higher than the peak obtained for nonCdMT+red QDs. This may be connected with Cd-MT saturation with heavy metals, and thus structure stabilization of MT and a preferable formation of aggregates (observed on chip-CE electropherogram at 41-43 s). The peaks of fluorescence intensity obtained for blue, green, and yellow QDs conjugated with nonCd-MT were higher than the peaks obtained for the same QDs with Cd-MT. This can be explained by greater affinity for nonCd-MT to bind Cd from QDs than Cd-MT (due to the saturated binding sites of this metal) (Carpene et al. 2007; Krizkova et al. 2010a).

Based on these results and taking into account the role of MT as a prognostic marker in cancerogenesis, chip-CE can be used as a technique to verify interaction between protein and NPs.

Acknowledgments The financial support from CEITEC-STIIP BR6240000 and Wroclaw Medical University Pbmn 178 is gratefully acknowledged.

Open Access This article is distributed under the terms of the Creative Commons Attribution 4.0 International License (http:// creativecommons.org/licenses/by/4.0/), which permits unrestricted use, distribution, and reproduction in any medium, provided you give appropriate credit to the original author(s) and the source, provide a link to the Creative Commons license, and indicate if changes were made.

\section{References}

Alivisatos AP (1996) Semiconductor clusters, nanocrystals, and quantum dots. Science 271:933-937. doi:10.1126/science. 271.5251 .933

Andrews GK (2000) Regulation of metallothionein gene expression by oxidative stress and metal ions. Biochem Pharmacol 59:95-104 
Bizon A, Milnerowicz-Nabzdyk E, Zalewska M, Zimmer M, Milnerowicz H (2011) Changes in pro/antioxidant balance in smoking and non-smoking pregnant women with intrauterine growth restriction. Reprod Toxicol 32:360-367. doi:10.1016/j.reprotox.2011.08.007

Bousse L, Mouradian S, Minalla A, Yee H, Williams K, Dubrow $\mathrm{R}$ (2001) Protein sizing on a microchip. Anal Chem 73:1207-1212. doi:10.1021/ac0012492

Brannon-Peppas L, Blanchette JO (2012) Nanoparticle and targeted systems for cancer therapy. Adv Drug Deliv Rev 64:206-212. doi:10.1016/j.addr.2012.09.033

Bremner I, Beattie JH (1990) Metallothionein and the trace minerals. Ann. Rev Nutr 10:63-83. doi:10.1146/annurev. nu.10.070190.000431

Cai L, Klein JB, Kang YJ (2000) Metallothionein inhibits peroxynitrite-induced DNA and lipoprotein damage. J Biol Chem 275:38957-38960. doi:10.1074/jbc.C000593200

Carpene E, Andreani G, Isani G (2007) Metallothionein functions and structural characteristics. J Trace Elem Med Biol 21(Suppl 1):35-39. doi:10.1016/j.jtemb.2007.09.011

Chan WC, Nie S (1998) Quantum dot bioconjugates for ultrasensitive nonisotopic detection. Science 281:2016-2018

Chan WC, Maxwell DJ, Gao X, Bailey RE, Han M, Nie S (2002) Luminescent quantum dots for multiplexed biological detection and imaging. Curr Opin Biotechnol 13:40-46

Cherian MG, Jayasurya A, Bay BH (2003) Metallothioneins in human tumors and potential roles in carcinogenesis. Mutat Res 533:201-209

Chua CK, Pumera M (2013) Detection of silver nanoparticles on a lab-on-chip platform. Electrophoresis 34:2007-2010. doi:10.1002/elps.201200426

Chubatsu LS, Meneghini R (1993) Metallothionein protects DNA from oxidative damage. Biochem J 291(Pt 1):193-198

Coyle P, Philcox JC, Carey LC, Rofe AM (2002) Metallothionein: the multipurpose protein. Cellular and molecular life sciences 59:627-647

Craig-Schapiro R, Fagan AM, Holtzman DM (2009) Biomarkers of Alzheimer's disease. Neurobiol Dis 35:128-140. doi:10.1016/j.nbd.2008.10.003

Davis SR, Cousins RJ (2000) Metallothionein expression in animals: a physiological perspective on function. J Nutr 130:1085-1088

Derfus AM, Chan WCW, Bhatia SN (2004) Probing the cytotoxicity of semiconductor quantum dots. Nano Lett 4:11-18. doi:10.1021/N10347334

Doz F, Roosen N, Rosenblum ML (1993) Metallothionein and anticancer agents: the role of metallothionein in cancer chemotherapy. J Neurooncol 17:123-129

Drbohlavova J, Adam V, Kizek R, Hubalek J (2009) Quantum dots - characterization, preparation and usage in biological systems. Int J Mol Sci 10:656-673. doi:10.3390/ ijms 10020656

Duan JL, Song LX, Zhan JH (2009) One-pot synthesis of highly luminescent CdTe quantum dots by microwave irradiation reduction and their $\mathrm{Hg} 2+$-sensitive properties. Nano Res 2:61-68. doi:10.1007/s12274-009-9004-0

Dubois F, Mahler B, Dubertret B, Doris E, Mioskowski C (2007) A versatile strategy for quantum dot ligand exchange. J Am Chem Soc 129:482-483. doi:10.1021/ja067742y
Duncan KER, Stillman MJ (2006) Metal-dependent protein folding: metallation of metallothionein. J Inorg Biochem 100:2101-2107. doi:10.1016/j.jinorgbio.2006.09.005

Frasco MF, Chaniotakis N (2010) Bioconjugated quantum dots as fluorescent probes for bioanalytical applications. Anal Bioanal Chem 396:229-240. doi:10.1007/s00216-0093033-0

Gao X, Yang L, Petros JA, Marshall FF, Simons JW, Nie S (2005) In vivo molecular and cellular imaging with quantum dots. Curr Opin Biotechnol 16:63-72. doi:10.1016/j. copbio.2004.11.003

Grieve K, Mulvaney P, Grieser F (2000) Synthesis and electronic properties of semiconductor nanoparticles/quantum dots. Curr Opin Colloid Interface Sci 5:168-172. doi:10. 1016/S1359-0294(00)00050-9

Hamer DH (1986) Metallothionein. Ann Rev Biochem 55:913-951. doi:10.1146/annurev.biochem.55.1.913

Hong SH, Gohya M, Ono H, Murakami H, Yamashita M, Hirayama N, Murooka Y (2000) Molecular design of novel metal-binding oligomeric human metallothioneins. Appl Microbiol Biotechnol 54:84-89

Hoshino A et al (2004) Physicochemical properties and cellular toxicity of nanocrystal quantum dots depend on their surface modification. Nano Lett 4:2163-2169. doi:10.1021/ $\mathrm{N} 1048715 \mathrm{~d}$

Kagi JH, Schaffer A (1988) Biochemistry of metallothionein. Biochemistry 27:8509-8515

Karotki AV, Vasak M (2009) Reaction of human metallothionein-3 with cisplatin and transplatin. J Biol Inorg Chem 14:1129-1138. doi:10.1007/s00775-009-0557-x

Koberle B, Tomicic MT, Usanova S, Kaina B (2010) Cisplatin resistance: preclinical findings and clinical implications. Biochim Biophys Acta 1806:172-182. doi:10.1016/j. bbcan.2010.07.004

Krizkova S, Adam V, Kizek R (2009a) Study of metallothionein oxidation by using of chip CE. Electrophoresis 30:4029-4033. doi:10.1002/elps.200900226

Krizkova S, Fabrik I, Adam V, Hrabeta J, Eckschlager T, Kizek R (2009b) Metallothionein-a promising tool for cancer diagnostics. Bratisl Lek Listy 110:93-97

Krizkova S, Masarik M, Eckschlager T, Adam V, Kizek R (2010a) Effects of redox conditions and zinc(II) ions on metallothionein aggregation revealed by chip capillary electrophoresis. J Chromatogr A 1217:7966-7971. doi:10. 1016/j.chroma.2010.07.022

Krizkova S et al (2010b) Serum metallothionein in newly diagnosed patients with childhood solid tumours. Acta Biochim Pol 57:561-566

Krizkova S et al (2011) Electrophoretic fingerprint metallothionein analysis as a potential prostate cancer biomarker. Electrophoresis 32:1952-1961. doi:10.1002/elps.201000519

Liu Y, Miyoshi H, Nakamura M (2007) Nanomedicine for drug delivery and imaging: a promising avenue for cancer therapy and diagnosis using targeted functional nanoparticles. Int $\mathrm{J}$ Cancer (Journal international du cancer) 120:2527-2537. doi:10.1002/ijc.22709

Manso Y et al (2012) Characterization of the role of metallothionein-3 in an animal model of Alzheimer's disease. Cell Mol life Sci 69:3683-3700. doi:10.1007/s00018-0121047-9 
Margoshes M, Vallee BL (1957) A cadmium protein from equine kidney cortex. J Am Chem Soc 79:4813-4814. doi:10.1021/Ja01574a064

Michalet X et al (2005) Quantum dots for live cells, in vivo imaging, and diagnostics. Science 307:538-544. doi:10. 1126/science. 1104274

Milnerowicz H, Bizon A (2010) Determination of metallothionein in biological fluids using enzyme-linked immunoassay with commercial antibody. Acta Biochim Pol 57:99-104

Minami T, Ichida S, Kubo K (2002) Study of metallothionein using capillary zone electrophoresis. J Chromatogr B 781:303-311

Mitchell GP, Mirkin CA, Letsinger RL (1999) Programmed assembly of DNA functionalized quantum dots. J Am Chem Soc 121:8122-8123. doi:10.1021/ja991662v

Miyawaki A, Sawano A, Kogure T (2003) Lighting up cells: labelling proteins with fluorophores. Nature Cell Biology 5:S1-S7. doi:10.1038/ncb1031

Moffatt P, Denizeau F (1997) Metallothionein in physiological and physiopathological processes. Drug Metab Rev 29:261-307

Murdock RC, Braydich-Stolle L, Schrand AM, Schlager JJ, Hussain SM (2008) Characterization of nanomaterial dispersion in solution prior to In vitro exposure using dynamic light scattering technique. Toxicol Sci 101:239-253. doi:10.1093/toxsci/kfm240

Namdarghanbari M, Wobig W, Krezoski S, Tabatabai NM, Petering DH (2011) Mammalian metallothionein in toxicology, cancer, and cancer chemotherapy. J Biol Inorg Chem 16:1087-1101. doi:10.1007/s00775-011-0823-6

Nielson KB, Atkin CL, Winge DR (1985) Distinct metal-binding configurations in metallothionein. $\mathrm{J}$ Biol Chem 260:5342-5350

Niemeyer CM (2001) Nanoparticles, proteins, and nucleic acids: Biotechnology meets materials science. Angew Chem Int Edit 40:4128-4158. doi:10.1002/15213773(20011119)40:22<4128:Aid-Anie4128>3.0.Co;2-S

Palumaa P, Vasak M (1992) Binding of inorganic phosphate to the cadmium-induced dimeric form of metallothionein from rabbit liver. Eur J Biochem/FEBS 205:1131-1135

Petersen JR, Okorodudu AO, Mohammad A, Payne DA (2003) Capillary electrophoresis and its application in the clinical laboratory. Clinica Chimica Acta 330:1-30

Pons T, Uyeda HT, Medintz IL, Mattoussi H (2006) Hydrodynamic dimensions, electrophoretic mobility, and stability of hydrophilic quantum dots. J Phys Chem B 110:20308-20316. doi:10.1021/jp065041h

Rana S, Yeh YC, Rotello VM (2010) Engineering the nanoparticle-protein interface: applications and possibilities. Curr Opin Chem Biol 14:828-834. doi:10.1016/j. cbpa.2010.10.001

Rao J, Dragulescu-Andrasi A, Yao H (2007) Fluorescence imaging in vivo: recent advances. Curr Opin Biotechnol 18:17-25. doi:10.1016/j.copbio.2007.01.003

Richards MP, Beattie JH (1995) Comparison of different techniques for the analysis of metallothionein isoforms by capillary electrophoresis. J Chromatogr B 669:27-37

Righetti PG, Sebastiano R, Citterio A (2013) Capillary electrophoresis and isoelectric focusing in peptide and protein analysis. Proteomics 13:325-340. doi:10.1002/pmic. 201200378

Roco MC (2003) Nanotechnology: convergence with modern biology and medicine. Curr Opin Biotechnol 14:337-346

Rosenthal SJ, Chang JC, Kovtun O, McBride JR, Tomlinson ID (2011) Biocompatible quantum dots for biological applications. Chem Biol 18:10-24. doi:10.1016/j.chembiol. 2010.11.013

Ruttkay-Nedecky B et al (2013) The role of metallothionein in oxidative stress. Int J Mol Sci 14:6044-6066. doi:10.3390/ ijms 14036044

Ryvolova M, Hynek D, Skutkova H, Adam V, Provaznik I, Kizek R (2012) Structural changes in metallothionein isoforms revealed by capillary electrophoresis and Brdicka reaction. Electrophoresis 33:270-279. doi:10.1002/elps. 201100312

Sabolic I, Breljak D, Skarica M, Herak-Kramberger CM (2010) Role of metallothionein in cadmium traffic and toxicity in kidneys and other mammalian organs. Biometals 23:897-926. doi:10.1007/s10534-010-9351-z

Salata O (2004) Applications of nanoparticles in biology and medicine. J Nanobiotechnol 2:3. doi:10.1186/1477-3155-2-3

Sanvicens N, Marco MP (2008) Multifunctional nanoparticlesproperties and prospects for their use in human medicine. Trends Biotechnol 26:425-433. doi:10.1016/j.tibtech. 2008.04.005

Shen JC, Liu J, Zhuang ZX, Wang XR, Lee FS (2006) Investigation of zinc binding metallothioneins' polymerization in tris(hydroxymethyl)-aminomethane buffer by coupling of size exclusion chromatography with electrospray ionization mass spectrometry. Talanta 69:988-995. doi:10.1016/ j.talanta.2005.12.002

Sieradzka E, Witt K, Milnerowicz H (2014) The application of capillary electrophoresis techniques in toxicological analysis. Biomed Chromatogr 28:1507-1513. doi:10.1002/ bmc. 3234

Silva AC, Silva MJ, da Luz FA, Silva DP, de Deus SL, Dantas NO (2014) Controlling the cytotoxicity of CdSe magicsized quantum dots as a function of surface defect density. Nano Lett 14:5452-5457. doi:10.1021/n15028028

Simpkins CO (2000) Metallothionein in human disease. Cell Mol Biol 46:465-488

Skalickova S et al (2013) Study of interaction between metallothionein and CdTe quantum dots. Chromatographia 76:345-353. doi:10.1007/s10337-013-2418-6

Smejkal P, Foret F (2012) Microfluidics in bioanalytical instrumentation. Chem Listy 106:104-112

Smith AM, Gao XH, Nie SM (2004) Quantum dot nanocrystals for in vivo molecular and cellular imaging. Photochem Photobiol 80:377-385. doi:10.1562/0031-8655(2004)08 $0<0377$ :Qdnfiv $>2.0$. Co; 2

Sogawa N et al (2013) Protective effect of cepharanthin on cisplatin-induced renal toxicity through metallothionein expression. Life Sci 92:727-732. doi:10.1016/j.1fs.2013. 01.031

Sturzenbaum SR et al (2013) Biosynthesis of luminescent quantum dots in an earthworm. Nat Nanotechnol 8:57-60. doi:10.1038/nnano.2012.232

Swinney K, Bornhop DJ (2000) Detection in capillary electrophoresis Electrophoresis 21:1239-1250. doi:10.1002/ 
(SICI)1522-2683(20000401)21:7<1239:AID-ELPS1239> 3.0.CO;2-6

Terai T, Nagano T (2013) Small-molecule fluorophores and fluorescent probes for bioimaging. Pflugers Arch 465:347-359. doi:10.1007/s00424-013-1234-z

Thormann W, Lurie IS, McCord B, Marti U, Cenni B, Malik N (2001) Advances of capillary electrophoresis in clinical and forensic analysis (1999-2000). Electrophoresis 22:4216-4243. doi:10.1002/1522-2683(200111)22:19<42 16:AID-ELPS4216>3.0.CO;2-W

Tmejova K et al (2014) Study of metallothionein-quantum dots interactions. Colloids Surf B 117:534-537. doi:10.1016/j. colsurfb.2014.03.013

Trabelsi H, Azzouz I, Sakly M, Abdelmelek H (2013) Subacute toxicity of cadmium on hepatocytes and nephrocytes in the rat could be considered as a green biosynthesis of nanoparticles. Int J Nanomed 8:1121-1128. doi:10.2147/ IJN.S39426

Uchida Y, Takio K, Titani K, Ihara Y, Tomonaga M (1991) The growth inhibitory factor that is deficient in the Alzheimer's disease brain is a 68 amino acid metallothionein-like protein. Neuron 7:337-347
Vasak M, Meloni G (2011) Chemistry and biology of mammalian metallothioneins. J Biol Inorg Chem 16:10671078. doi:10.1007/s00775-011-0799-2

Waalkes MP, Harvey MJ, Klaassen CD (1984) Relative in vitro affinity of hepatic metallothionein for metals. Toxicol Lett 20:33-39. doi:10.1016/0378-4274(84)90179-6

Wang LY, Li YD (2007) Controlled synthesis and luminescence of lanthanide doped NaYF4 nanocrystals. Chem Mater 19:727-734. doi:10.1021/Cm061887m

Wang $\mathrm{H}$ et al (2006) Solution structure and dynamics of human metallothionein-3 (MT-3). FEBS Lett 580:795-800. doi:10.1016/j.febslet.2005.12.099

Zalewska M, Bizon A, Milnerowicz H (2011) Comparison of capillary electrophoretic techniques for analysis and characterization of metallothioneins. J Sep Sci 34:3061-3069. doi:10.1002/jssc.201100379

Zalewska M, Trefon J, Milnerowicz H (2014) The role of metallothionein interactions with other proteins. Proteomics 14:1343-1356. doi:10.1002/pmic.201300496

Zhu ZF, Lu JJ, Liu SR (2012) Protein separation by capillary gel electrophoresis: a review. Anal Chim Acta 709:21-31. doi:10.1016/j.aca.2011.10.022 